\title{
Directional Darwinian Selection in proteins
}

\author{
David A McClellan ${ }^{1,2}$ \\ From The 9th Annual Biotechnology and Bioinformatics Symposium (BIOT 2012) \\ Provo, UT, USA. 25-26 October 2012
}

\begin{abstract}
Background: Molecular evolution is a very active field of research, with several complementary approaches, including $d N / d S, H O N 90, M M 01$, and others. Each has documented strengths and weaknesses, and no one approach provides a clear picture of how natural selection works at the molecular level. The purpose of this work is to present a simple new method that uses quantitative amino acid properties to identify and characterize directional selection in proteins.
\end{abstract}

Methods: Inferred amino acid replacements are viewed through the prism of a single physicochemical property to determine the amount and direction of change caused by each replacement. This allows the calculation of the probability that the mean change in the single property associated with the amino acid replacements is equal to zero ( $H_{0}: \mu=0$; i.e., no net change) using a simple two-tailed t-test.

Results: Example data from calanoid and cyclopoid copepod cytochrome oxidase subunit I sequence pairs are presented to demonstrate how directional selection may be linked to major shifts in adaptive zones, and that convergent evolution at the whole organism level may be the result of convergent protein adaptations.

Conclusions: Rather than replace previous methods, this new method further complements existing methods to provide a holistic glimpse of how natural selection shapes protein structure and function over evolutionary time.

\section{Background}

Natural selection, as first outlined by Charles Darwin, acts on phenotypes:

"She [natural selection] can act on every internal organ, on every shade of constitutional difference, on the whole machinery of life...Under nature, the slightest difference of structure or constitution may well turn the nicelybalanced scale in the struggle for life, and so be preserved...It may be said that natural selection is daily and hourly scrutinizing, throughout the world, every variation, even the slightest; rejecting that which is bad, preserving and adding up all that is good." [1].

We can think of natural selection as collecting adaptations that optimize an organism's survival, reproductive success, and fecundity in a given environment or habitat. As Darwin explicitly states above, this process is not limited to the phenotypes of the whole organism; it works on

\footnotetext{
Correspondence: david.mcclellan@uafs.edu

${ }^{1}$ Department of Biology, University of Arkansas-Fort Smith, Fort Smith, AR 72913, USA
}

Full list of author information is available at the end of the article "every variation, even the slightest." Although we sometimes think of proteins in this way, there currently is not a consistently reliable method for identifying and characterizing the evolution of protein phenotypes. This being stated, science is currently faced with the challenge of assessing the impact that anthropogenic climate change is likely to have with potentially catastrophic effects at the base of the food chain on the molecular level. The scientific community's efforts to produce realistic solutions to the big problems associated with climate change will be greatly enhanced by the development of more robust analytical methods for comprehensively characterizing the effects of natural selection in terms of the biochemistry and physics of protein structure, function, and interactions.

Several statistical methods for identifying and characterizing selection at the molecular level have been proposed since the genetic code was determined in the 1960s. Of these, three classes of methods dominate the literature. The first, and most significant, is the family of methods that implements one of many variations of the nonsynonymous-to-synonymous substitution rate ratio, 
or $d N / d S$ (e.g., [2-15]). Briefly, this approach compares the rate of nonsynonymous $(d N)$, or amino acid changing, nucleotide substitutions with the rate of synonymous $(d S)$, or silent, nucleotide substitution. When $d N$ is significantly greater than $d S$, the system is said to have been influenced by positive selection, when $d N=d S$, the system is said to be neutral, and $d N<d S$ indicates negative selection. This family of methods is broadly accepted and implemented, and has enjoyed a great deal of success. This simple model, however, has several shortcomings, including problems with the underlying assumptions (e.g., [16-19]) and difficulties accurately estimating rates when divergences are very small and great, and is not sensitive enough to detect natural selection in some protein coding genes when it is known to have taken place (e.g., [20-22]).

As a reaction to weaknesses of $d N / d S$ approaches, Hughes et al. [23] presented a similar approach (hereafter referred to as HON90) that compares proportions of conservative $\left(p_{N C}\right)$ and radical $\left(p_{N R}\right)$ amino acid replacement in terms of qualitative properties of amino acids to detect selection promoting charge profile diversity in class I MHC proteins. When $p_{N R}>p_{N C}$, the property of interest is said to have changed more than would be expected under random conditions. The Hughes et al. study [23] was the first to implement amino acid properties-in this case charge, polarity, hydrophobicity, and volume-to identify selection at the protein level. From a conceptual standpoint, this approach presented a method to assess patterns of amino acid replacement using the phenotypes of proteins, thus providing an avenue of analysis more consistent with Darwin's original definition of natural selection. This protein-level phenotypic approach has since been implemented several times and has yielded encouraging results (e.g., [24-28]).

In an effort to tap into the wealth of information afforded by the implementation of quantitative amino acid properties, researchers have expanded upon the HON90 approach in a number of ways, including the use of a spectrum of magnitude categories [18,29], a sliding window [30], accuracy benchmarking [31], and potential uses for characterizing single amino acid replacements [32]. These approaches (hereafter referred to as MM01 methods) take the underlying pattern of nucleotide composition into account. The collective identity of properties that individually yield positive statistical results provides clues that link specific genetic variants to selective advantages and disadvantages afforded by known changes in ambient environment $[18,33,34]$. The robustness of the results yielded by MM01 approaches is greatly enhanced by the wealth of information emerging from crystallography and magnetic resonance experiments that determine protein structures with a high degree of precision and accuracy. Results localized to protein regions of known structures and functions provide evidence useful for comprehensively characterizing protein function evolution [30,34-38].

\section{Existing solutions fall short}

Reconstructing evolutionary events at the molecular level and diagnosing them in terms of natural selection has been an extraordinary challenge. Each individual point mutation carries with it just a small quantum of information. Patterns emerge as these quanta accumulate over evolutionary time. Oversimplifying models used to assess patterns of evolutionary information emerging from molecular data results in a net loss of analytical yield. Overparameterizing models has the opposite effect, producing more detail than can be realistically supported by the data. When studying a phenomenon as nuanced and multifaceted as molecular evolution, striking a happy medium between oversimplification and overparameterization is extremely difficult. Researchers want to squeeze every ounce of information from their data without seeing patterns that are not really there.

It is not surprising that $d N / d S$ approaches sometimes ignore signs of natural selection that other methods pick up. $d N / d S$ is a simple method, with several documented limitations [16-22]. The HON90 approach takes a step forward by incorporating amino acid properties, but the number of qualitative properties is limited; if the evolution of protein-coding gene sequences cannot be linked to charge, polarity, hydrophobicity, volume, or just a handful of other properties, negative results will be produced. Although these properties are important in terms of protein function, they likely are not the only properties affected by natural selection.

MM01 approaches present several advantages over $d N / d S$ and HON90 methods (e.g., [18,30,35,36,39-45]). However, in an effort to force a greater information yield from the data, this method may be parameterizing systems to the point that accuracy suffers $[31,32,46]$. Clearly, this third class of approaches performs better in some circumstances, such as when divergences are very great and rates of synonymous change are underestimated [18], or when divergences are very small and synonymous changes have not had time to accumulate [32].

\section{Methods}

The high frequency with which new genomes and metagenomes are being produced also suggests that a method with the potential for high-throughput that does not require information from underlying nucleotides is needed. Gene annotations produce a huge number of BLAST results $[47,48]$. Many of these are in the form of aligned protein, and not nucleotide, sequences. None of the methods outlined above are capable of screening this type of information for signs of molecular adaptation and 
cannot be utilized for studying adaptive changes at the genomic or metagenomic levels.

There is at least one aspect of physicochemical evolution that has been largely overlooked: the direction of selection. One exception is the study by Merritt and Quattro [27]. They identified a case in which positive selection resulted in a biased accumulation of negatively charged amino acids after a gene duplication event. However, changes in charge are generally rare in protein evolution $[27,49,50]$ and, as discussed, the possible qualitative properties to test in the way Merritt and Quattro present are few in number. Testing for directional shifts in quantitative properties, of which there are now several hundred catalogued in the Japanese database AAindex [51], will allow for more comprehensive exploration of property space, and will likely result in a more clearly resolved vision of how proteins adapt to the specific needs of organisms as they evolve in changing habitats. Such a new method, when coupled with existing methods, will provide a full set of analytical tools for identifying and characterizing molecular adaptation in a biologically meaningful way.

A method similar to that presented by Merritt and Quattro [27] that allows for the implementation of quantitative physicochemical amino acid properties will require a different statistical test. Inferred amino acid replacements will be viewed through the prism of a single physicochemical property to determine the amount and direction of change caused by each replacement. This will allow the calculation of the probability that the mean change in the single property associated with the amino acid replacements is equal to zero $\left(\mathrm{H}_{0}: \mu=0\right.$; i.e., no net change) using a simple two-tailed t-test.

The novel aspect of this new method is its criterion. It evaluates amino acid replacements multi-dimensionally across a great number of physicochemical amino acid properties, and identifies instances of several amino acid replacements across several sites, evolving across phylogenetic space in the same physicochemical direction in a single dimension of property space. This approach makes the study of molecular evolution more applicable to studies that link patterns of amino acid replacement with environmental changes through time or space. A directional approach represents a return to the fundamental concept that selection affects phenotypes, while at the same time simplifying implementation. By so doing, interpretation of results will be less ambiguous.

The new method begins with a list of amino acid differences that includes the location of each in the context of the linear sequence of nucleotide codons and/or amino acids, depending on the input data. This list can be generated using an ancestral character-state reconstruction algorithm (such as codeml [52]) if the input is a multiple sequence alignment and a phylogenetic structure, or by pairwise comparison if the input is the results of a
BLAST search $[47,48]$. From this list, the magnitude and direction (i.e., an increase or a decrease) of change in each amino acid property under consideration is inferred. A simple two-tailed t-test may be performed for each property to statistically evaluate the null hypothesis that the net change is equal to zero. The value of the t-test statistic is calculated using simple established equations:

$$
\begin{aligned}
& t=\frac{\bar{X}}{s_{\bar{X}} / \sqrt{N}} \\
& s_{\bar{X}}=\sqrt{\frac{\Sigma X_{i}^{2}-\frac{\left(\Sigma X_{i}\right)^{2}}{N}}{N-1}}
\end{aligned}
$$

Here $X_{i}$ is the value of the change in amino acid property for each inferred amino acid difference, $i$, and $N$ is the total number of amino acid differences. In the example below (Table 1), the value of $X_{i}$ for the difference at residue site 82 is +7.0 , while the value of $N$ is 15 .

The data may be partitioned in several different ways: A sliding window may be implemented to evaluate potential clustering of unidirectional changes; known or estimated secondary structures may be used to group amino acid differences according to the structural components of the protein; the range of amino acid sites corresponding to the functional domains of the protein may be used. How the data are partitioned is largely contingent on the scientific question, the amount and type of differences in the data, and the amount of supporting structure and function

Table 1 Directional selection analysis of Pan and Homo SAGE1

\begin{tabular}{cccc}
\hline Residue & Pan & Homo & $\boldsymbol{\Delta}$ Hydropathy \\
\hline 82 & Cys & Arg & +7.0 \\
92 & Val & Ala & +2.4 \\
160 & Arg & His & -1.3 \\
450 & Gln & Arg & +1.0 \\
507 & Asp & Val & -7.7 \\
523 & Ser & Thr & -0.1 \\
563 & Val & Ala & +2.4 \\
582 & Val & Asp & +7.7 \\
605 & Phe & Leu & -1.0 \\
672 & Ala & Thr & +2.5 \\
675 & Ser & Asn & +2.7 \\
694 & Thr & Ala & -2.5 \\
754 & Cys & Arg & +7.0 \\
802 & Val & Ala & +2.4 \\
805 & Leu & Ser & +4.6 \\
& & Net Change & +27.1 \\
\hline
\end{tabular}

Residue sites of the 15 Pan troglodytes and Homo sapiens SAGE1 (inferred from XM_001137139 and NM_018666, respectively) protein differences, with character states and net change in hydropathy [54]. 
information available. In each case, care must be taken to partition the data in biologically meaningful ways that test specific hypotheses.

There are over 500 physicochemical amino acid properties on the AAindex database [51] available to assess amino acid differences. For the purposes of this study, the 25 properties in Table 2 were chosen to be representative of the breadth of amino acid property space. These properties describe aspects of proteins that are important to overall structure (e.g., molecular size, hydrophobicity, secondary structures) and function (e.g., ionization, non-bonded energy, solvent accessibility); properties that can potentially be affected by natural selection.

Together, these four complementary methods will enable more robust evaluation of data than is possible with any single method: $d N / d S$ methods focus on patterns of nucleotide substitution; HON90 looks at phenotypic patterns across amino acid changes; MM01 methods emphasize patterns among the most radical changes; the new method detects localized directional shifts in protein phenotypes. Furthermore, certain methods are able to more easily accommodate different data types. All of the methods can assess multiple protein-coding nucleotide sequence alignments with an accompanying phylogenetic structure, but $d N / d S$ methods, for example, are unable to evaluate blastp output because there is no way to estimate the rate of synonymous change in the encoding DNA sequences from aligned amino acid sequences. The new directional selection method will easily accept blastp output because it does not require information about the underlying pattern of nucleotides or the governing genetic code.

\section{Results and discussion}

\section{Directional selection linked to Habitat Shifts}

Several marine and freshwater calanoid copepod cytochrome oxidase subunit I (COI) sequence pairs were considered. The first approximately 650 nucleotides of the cytochrome oxidase subunit 1 coding region for each were obtained from the Barcode of Life Database (http://www. barcodinglife.com) and evaluated using the directional selection approach. The comparison of Calanus hyperboreus (marine) and Mastigodiaptomus montezumae (freshwater) is representative (GenBank accession numbers FJ602504 and EU770508, respectively). Interestingly, the first 650 nucleotides encode all of the components of the first COI proton pump [53]. There are 11 amino acid differences within the first 215 amino acid residue sites for this species pair. These replacements have resulted in radical changes in several physicochemical properties. None of the properties were implicated in the proton output region of the protein $(p<0.05)$, but three properties affected the proton input region: one that describes hydrophobicity $\left(H_{p}\right)$, one for polarity $\left(P_{r}\right)$, and one for tertiary structure $(F)$. Collectively, these properties, coupled with their direction of change, indicate that the proton input region became less hydrophobic, more polar, and more structural malleability during calanoid adaptation to freshwater, resulting in a more direct and less energetically expensive path for hydrogen ions to penetrate the membrane and enter the proton pump.

Several marine and freshwater cyclopoid copepod cytochrome oxidase subunit I (COI) sequence pairs were considered as well. Of these, the comparison of Oithona similis (marine) and Thermocyclops inversus (freshwater) is representative (GenBank accession numbers EU599544 and EU770551, respectively). There are 40 amino acid differences within the first 215 residue sites of COI for this species pair. Five properties yielded statistically significant directional results $(p<0.05)$ across the entire alignment, including $V^{0}, P_{r}, p, \mu$, and $H_{t}$. Like the calanoid data, the cyclopoid data failed to exhibit positive results in the proton output region. The proton input region, however, experienced significant directional change in 12 properties (Table 3). The identity of the properties and the direction of change were similar to the calanoid results, indicating a decrease in hydrophobicity $\left(h, H_{p}, H_{t}\right)$, an increase in polarity $\left(P_{r}, p\right)$, and increased structural malleability $\left(N_{a}, B_{r}, F\right)$, but cyclopoids also exhibited a decrease in molecular size $\left(B_{l}, V^{0}\right)$ and total non-bonded energy $\left(E_{t}\right)$, and an increase in turn tendency $\left(P_{t}\right)$. Collectively, these results suggest an even more direct and less energetically expensive path for hydrogen ions to enter the proton pump than exhibited by the calanoids.

Interestingly, the calanoid and cyclopoid results appear parallel at the property level even though none of the specific sites affected were the same. To illustrate even the subtle parallel shifts in properties, Table 3 also includes those properties that yielded results at a lower significance $(p=0.1)$. Every property affected during calanoid adaptation to freshwater was also affected during cyclopoid adaptation to freshwater, and in the same direction. Cyclopoids had a greater number of affected properties likely due to a greater accumulation of amino acid replacements.

The discovery that these two lineages of copepods found parallel routes for COI functional adaptation is the most exciting conclusion of these results. These findings suggest that the amazing amount of convergence in the natural world may be the result of a limited number of alternative physicochemical strategies. This partially explains how independently evolving proteins can converge upon similar structures and functions when sequence identity remains low. Furthermore, the consistency of these results 
Table 2 Quantitative physicochemical amino acid properties

\begin{tabular}{|c|c|c|c|}
\hline Category/Property & Symbol & Reference & Description $^{a}$ \\
\hline \multicolumn{4}{|l|}{ Hydrophobicity } \\
\hline Hydropathy & $h$ & [54] & $\begin{array}{l}\text { The hydrophilic and hydrophobic inclinations of a given residue side chain in terms of transfer } \\
\text { of free energy. }\end{array}$ \\
\hline $\begin{array}{r}\text { Surrounding } \\
\text { hydrophobicity }\end{array}$ & $H_{p}$ & [55] & $\begin{array}{l}\text { The average sum of residue hydrophobic indices within an optimum sphere of } 8 \AA \text { radius } \\
\text { around a residue in protein crystals }(\mathrm{kcal} / \mathrm{mol}) \text {. }\end{array}$ \\
\hline $\begin{array}{l}\text { Thermodynamic transfer } \\
\text { hydrophobicity }\end{array}$ & $H_{t}$ & [56] & $\begin{array}{l}\text { The experimental values of Noazaki \& Tanford [57] combined with values of Zimmerman et al. } \\
\text { [58] adjusted to the same scale ( } \mathrm{kcal} / \mathrm{mol}) \text {. }\end{array}$ \\
\hline \multicolumn{4}{|l|}{ lonization Constants } \\
\hline Equilibrium constant & $p K^{\prime}$ & [56] & The ionizable character of the carboxyl group (pH units). \\
\hline Isoelectric point & $\mathrm{pH}_{i}$ & [58] & $\begin{array}{l}\text { The isoionic point of the free amino acid, including the ionizable character of the entire residue } \\
\text { ( } \mathrm{pH} \text { units). }\end{array}$ \\
\hline \multicolumn{4}{|c|}{ Molecular Size \& Composition } \\
\hline Bulkiness & $B_{l}$ & [58] & The ratio of the side chain volume to length (i.e., the average cross section of the chain) $\left(\AA^{2}\right)$. \\
\hline Composition & c & [59] & $\begin{array}{l}\text { The atomic weight ratio of the non-carbon elements in the end groups or rings to carbons in } \\
\text { the side chain. }\end{array}$ \\
\hline Molecular weight & $M_{w}$ & {$[60]$} & The mass of the atoms constituting the residue. \\
\hline Partial specific volume & p & [61] & The reciprocal of density $\left(\mathrm{m}^{3} \mathrm{~mol}^{-1} \times 10^{-6}\right)$. \\
\hline \multicolumn{4}{|l|}{ Non-bonded Energy } \\
\hline Long range energy & $E_{l}$ & {$[62]$} & $\begin{array}{l}\text { The energy between two amino acids separated further than } 10 \text { residues (i.e., due to } \\
\text { electrostatic and Van der Waals forces) ( } \mathrm{kcal} / \mathrm{mol}) \text {. }\end{array}$ \\
\hline $\begin{array}{l}\text { Short and medium range } \\
\text { energy }\end{array}$ & $E_{s m}$ & {$[62]$} & $\begin{array}{l}\text { The sum of the energy between 1) main chain atoms of a residue and its own side chain } \\
\text { atoms, and 2) two residues located within } 10 \text { residues along the chain ( } \mathrm{kcal} / \mathrm{mol}) \text {. }\end{array}$ \\
\hline Total non-bonded energy & $E_{t}$ & {$[62]$} & Sum of average short, medium, and long range non-bonded energies ( $\mathrm{kcal} / \mathrm{mol})$. \\
\hline \multicolumn{4}{|l|}{ Polarity \& Polarizability } \\
\hline Polar requirement & Pr & [63] & $\begin{array}{l}\text { The slope of the line regressing } \log R_{M} \text { and the mol fraction of water in the pyrimidine-water } \\
\text { solvent }\left(R_{M}=1 / R_{F}-1 \text {, where } R_{F} \text { is the chromatographic index [58]). }\right.\end{array}$ \\
\hline Polarity & $p$ & [59] & The average of $P_{r}$ and $P_{A}\left(P_{A}=13.66-14.85 R_{F}\right)$. \\
\hline Refractive index & $\mu$ & [55] & $\begin{array}{l}\text { The measure of the polarizability of a residue (i.e., the reciprocal measure of its electrical stability } \\
\text { under an external field). }\end{array}$ \\
\hline \multicolumn{4}{|l|}{ Secondary Structure } \\
\hline Alpha-helical tendency & $P_{\alpha}$ & [64] & The average intrinsic property of a residue to adopt an alpha-helical conformation. \\
\hline Beta-structure tendency & $P_{\beta}$ & [64] & The average intrinsic property of a residue to adopt a beta-sheet conformation. \\
\hline Coil tendency & $P_{c}$ & [65] & A measure of the tendency that a particular residue will be found in a coil secondary structure. \\
\hline Helical contact area & $C_{a}$ & [66] & $\begin{array}{l}\text { The maximum area loss that could occur in going from an isolated } \alpha \text {-helix to a fully buried } \\
\text { environment in the complex }\left(\AA^{2}\right) \text {. }\end{array}$ \\
\hline Turn tendency & $P_{t}$ & [64] & The average intrinsic property of a residue to adopt a beta-turn conformation. \\
\hline \multicolumn{4}{|l|}{ Solvent Accessibility } \\
\hline $\begin{array}{l}\text { Solvent accessibility } \\
\text { reduction ratio }\end{array}$ & $R_{a}$ & {$[67]$} & $\begin{array}{l}\text { The ratio of solvent accessibility: the solvent accessibility of a residue in a hypothetically } \\
\text { extanded state over its accessibility in a native folded protein. }\end{array}$ \\
\hline \multicolumn{4}{|l|}{ Tertiary Structure } \\
\hline $\begin{array}{l}\text { Average number of } \\
\text { surrounding residues }\end{array}$ & $N_{a}$ & {$[67]$} & $\begin{array}{l}\text { The average number of residues surrounding a residue within the effective distance of } \\
\text { influence. }\end{array}$ \\
\hline Buriedness & $B_{r}$ & [61] & The average propensity of a residue to be found in the interior of a protein. \\
\hline Compressibility & $k^{0}$ & [61] & $\begin{array}{l}\text { The relative increase in the volume of the system per unit decrease in pressure }\left(\mathrm{m}^{3} \mathrm{~mol}^{-1} \mathrm{~Pa}^{-1} \times\right. \\
\left.10^{-15}\right) \text {. }\end{array}$ \\
\hline $\begin{array}{l}\text { Mean rms fluctuational } \\
\text { displacement }\end{array}$ & $F$ & [68] & $\begin{array}{l}\text { The relationship between the average amount of root-mean-square displacement of a residue } \\
\text { and its distance from the centroid of the protein }(\AA) \text {. }\end{array}$ \\
\hline
\end{tabular}

${ }^{a}$ Properties without defined units are dimensionless.

Twenty-five amino acid properties representative of the breadth of amino acid property space.

demonstrates how analyzing protein-coding genes in terms of changing protein phenotypes provides a link between the evolution of organisms and the influence of environmental variables, and hints at the actual causes of natural selection.

\section{Conclusions}

The methods for identifying and characterizing natural selection at the molecular level, $d N / d S$, HON90, and MM01, use different aspects of the evolutionary information locked in protein-coding sequencing sequences. 
Table 3 Results of directional selection analysis of marine and freshwater copepod COI

\begin{tabular}{|c|c|c|c|c|}
\hline \multirow[b]{2}{*}{ Properties } & \multicolumn{2}{|c|}{ Calanoids } & \multicolumn{2}{|c|}{ Cyclopoids } \\
\hline & $\begin{array}{l}\text { Proton } \\
\text { Input }\end{array}$ & $\begin{array}{l}\text { Proton } \\
\text { Output }\end{array}$ & $\begin{array}{l}\text { Proton } \\
\text { Input }\end{array}$ & $\begin{array}{l}\text { Proton } \\
\text { Output }\end{array}$ \\
\hline \multicolumn{5}{|c|}{ Hydrophobicity } \\
\hline$h$ & -- & & & \\
\hline$H_{p}$ & -- & & -- & \\
\hline$H_{t}$ & - & & - & \\
\hline \multicolumn{5}{|c|}{ lonization Constants } \\
\hline \multicolumn{5}{|l|}{$p K^{\prime}$} \\
\hline \multicolumn{5}{|l|}{$p H_{i}$} \\
\hline \multicolumn{5}{|c|}{ Molecular Size } \\
\hline$B_{l}$ & -- & & & \\
\hline \multicolumn{5}{|l|}{ c } \\
\hline$M_{w}$ & - & & & \\
\hline$v^{0}$ & $-\cdots$ & & - & \\
\hline \multicolumn{5}{|c|}{ Non-bonded Energy } \\
\hline$E_{l}$ & - & & & \\
\hline \multicolumn{5}{|l|}{$E_{s m}$} \\
\hline$E_{t}$ & -- & & & \\
\hline \multicolumn{5}{|c|}{ Polarity \& Polarizability } \\
\hline$P_{r}$ & +++ & & ++ & \\
\hline$p$ & +++ & & + & \\
\hline$\mu$ & -- & & - & \\
\hline \multicolumn{5}{|c|}{ Secondary Structure } \\
\hline \multicolumn{5}{|l|}{$P_{\alpha}$} \\
\hline \multicolumn{5}{|l|}{$P_{\beta}$} \\
\hline$P_{c}$ & + & & & \\
\hline$C_{a}$ & - & & - & \\
\hline$P_{t}$ & ++ & & & \\
\hline \multicolumn{5}{|c|}{ Solvent Accessibility } \\
\hline \multicolumn{5}{|l|}{$R_{a}$} \\
\hline \multicolumn{5}{|c|}{ Tertiary Structure } \\
\hline$N_{a}$ & -- & & & \\
\hline$B_{r}$ & -- & & - & \\
\hline$k^{0}$ & + & & & \\
\hline F & +++ & & ++ & \\
\hline
\end{tabular}

Properties among the 25 defined in Table 2 that experienced significant directional shifts as copepods evolved from being adapted to a marine habitat to life in freshwater $("+$ " indicates significant increases in the property, while "-" indicates significant decreases in the property; one symbol indicates significance at the $\alpha=0.1$ level, while two symbols indicate significance at the $\alpha=0.05$ level and three indicates $\alpha=0.02$ significance).

However, none of these methods are able to identify signs of adaptation in protein sequences without the aid of the underlying nucleotide information. A new method for identifying adaptation in either protein or protein-coding DNA sequences is presented. Collectively, the four methods will enable a more robust evaluation of existing data than is possible with any single method. Furthermore, the new directional selection method can tap the wealth of information in BLAST reports, like those emerging from genome and metagenome annotation efforts. It is likely that high-throughput analysis of annotation reports will provide a glimpse of the collective evolutionary forces that shape the morphologies and behaviors at the organismal level, especially as they evolve in a changing environment, providing a strong link between macroevolution and microevolution. Such a link will likely prove important to improving our understanding of how modern anthropogenic changes in global and local climates may be affecting vulnerable organisms over evolutionary time or at more accelerated rates.

\section{Competing interests}

There are no competing interests with regard to this research.

Authors' contributions

This research was performed by the sole author.

\section{Acknowledgements}

The author thanks Bigelow Laboratory for Ocean Sciences for support of this research. He also a acknowledges the many students who have worked on associated projects, especially S Woolley, J K Sailsbery, R G Christensen, A Fuchsman, and A Burchill. Furthermore, he thanks M J Clement and K A Crandall for numerous conversations and assistance mentoring students. He thanks G Wyngaard for help understanding copepods and their gene sequences. Finally, he thanks $G$ Shimmield and T Brailovskaya for advice and editing assistance.

\section{Declarations}

Funding for publication was provided by the Department of Biological Science at University of Arkansas-Fort Smith.

This article has been published as part of BMC Bioinformatics Volume 14 Supplement 13, 2013: Selected articles from the 9th Annual Biotechnology and Bioinformatics Symposium (BIOT 2012). The full contents of the supplement are available online at http://www.biomedcentral.com/ bmcbioinformatics/supplements/14/S13

\section{Authors' details}

'Department of Biology, University of Arkansas-Fort Smith, Fort Smith, AR 72913, USA. ${ }^{2}$ Bigelow Laboratory for Ocean Sciences, East Boothbay, ME 04544, USA.

Published: 1 October 2013

\section{References}

1. Darwin C: On the Origin of Species Harvard University Press, Cambridge, Massachusetts; 1964, 83-84, (facsimile of the First Edition, 1859).

2. Nei $M$, Gojobori T: Simple methods for estimating the numbers of synonymous and nonsynonymous nucleotide substitutions. Molecular Biology and Evolution 1986, 3:418-426.

3. Lee Y-H, Vacquier VD: The divergence of species-specific abalone sperm lysins is promoted by positive Darwinian selection. Biological Bulletin 1992, 182:97-104.

4. Li W-H: Unbiased estimation of the rates of synonymous and nonsynonymous substitution. J Molecular Evolution 1993, 36:96-99.

5. Nielsen R, Yang Z: Likelihood models for detecting positively selected amino acid sites and applications to the HIV-1 envelope gene. Genetics 1998, 148:929-936.

6. Yang Z, Nielsen R, Goldman N, Pedersen A-MK: Codon-substitution models for heterogeneous selection pressure at amino acid sites. Genetics 2000, 155:431-449.

7. Swanson WJ, Yang Z, Wolfner MF, Aquadro CF: Positive Darwinian selection drives the evolution of several female reproductive proteins in mammals. Proceedings of the National Academy of Sciences, USA 2001, 98:2509-2514.

8. Fares MA, Wolfe KH: Positive selection and subfunctionalization of duplicated CCT chaperonin subunits. Molecular Biology and Evolution 2003, 20:1588-1597. 
9. Chen L, Perlina A, Lee CJ: Positive selection detection in 40,000 human immunodeficiency virus (HIV) type 1 sequences automatically identifies drug resistance and positive fitness mutations in HIV protease and reverse transcriptase. J Virology 2004, 78:3722-3732.

10. Filip LC, Mundy NI: Rapid evolution by positive Darwinian selection in the extracellular domain of the abundant lymphocyte protein CD45 in primates. Molecular Biology and Evolution 2004, 21:1504-1511.

11. Pogson GH, Mesa KA: Positive Darwinian selection at the pantophysin (Pan I) locus in marine gadid fishes. Molecular Biology and Evolution 2004, 21:65-75.

12. Petersen L, Bollback JP, Dimmic M, Hubisz M, Nielsen R: Genes under positive selection in Escherichia coli. Genome Research 2007, 17:1336-1343.

13. Sabeti PC, Varilly P, Fry B, Lohmueller J, Hostetter E, Cotsapas C, Xie X, Byrne EH, McCarroll SA, Gaudet R, Schaffner SF, Lander ES, The International HapMap Consortium: Genome-wide detection and characterization of positive selection in human populations. Nature 2007, 449:913-918.

14. Kosiol C, Vinař $T$, de Fonseca RR, Hubisz MJ, Bustamante CD, Nielsen R, Siepel A: Patterns of positive selection in six mammalian genomes. PLoS Genetics 2008, 4:e1000144.

15. Metzger KJ, Thomas MA: Evidence of positive selection at codon sites localized in extracellular domains of mammalian CC motif chemokine receptor proteins. BMC Evolutionary Biology 2010, 10:139.

16. Hughes AL: Adaptive Evolution of Genes and Genomes Oxford University Press, Oxford, UK; 1999.

17. Gillespie JH: Population Genetics: A Concise Guide Johns Hopkins University Press, Baltimore, Maryland; 2004

18. McClellan DA, Palfreyman EJ, Smith MJ, Moss JL, Christensen RG, Sailsbery JK: Physicochemical evolution and molecular adaptation of the cetacean and artiodactyl cytochrome $b$ proteins. Molecular Biology and Evolution 2005, 22:437-455.

19. Hughes AL: Looking for Darwin in all the wrong places: The misguided quest for positive selection at the nucleotide sequence level. Heredity 2007, 99:364-373.

20. Wolfe KH, Sharp PM: Mammalian gene evolution: Nucleotide sequence divergence between mouse and rat. Journal of Molecular Evolution 1993, 37:441-456.

21. Crandall KA, Kelsey CR, Imamichi H, Lane HC, Salzman NP: Parallel evolution of drug resistance in HIV: Failure of nonsynonymous/ synonymous substitution rate ratio to detect selection. Molecular Biology and Evolution 1999, 16:372-382

22. Creevey CJ, Mclnerney JO: An algorithm for detecting directional and non-directional positive selection, neutrality and negative selection in protein coding DNA sequences. Gene 2002, 300:43-51.

23. Hughes AL, Ota T, Nei M: Positive Darwinian selection promotes charge profile diversity in the antigen-binding cleft of Class I majorhistocompatibility-complex molecules. Molecular Biology and Evolution 1990, 7:515-524

24. Swanson WJ, Vacquier VD: Extraordinary divergence and positive Darwinian selection in a fusagenic protein coating the acrosomal process of abalone spermatozoa. Proceedings of the National Academy of Sciences, USA 1995, 92:4957-4961.

25. Metz EC, Palumbi SR: Positive selection and sequence rearrangements generate extensive polymorphism in the gamete recognition protein bindin. Molecular Biology and Evolution 1996, 13:397-406.

26. Zhang J: Rates of conservative and radical nonsynonymous nucleotide substitutions in mammalian nuclear genes. Journal of Molecular Evolution 2000, 50:56-68.

27. Merritt TJS, Quattro JM: Evidence for a period of directional selection following gene duplication in a neutrally expressed locus of triosephosphate isomerase. Genetics 2001, 159:689-697.

28. Van de Peer $Y$, Taylor JS, Braasch I, Meyer A: The ghost of selection past: Rates of evolution and functional divergence of anciently duplicated genes. Journal of Molecular Evolution 2001, 53:436-446.

29. McClellan DA, McCracken KG: Estimating the influence of selection on the variable amino acid sites of the cytochrome $b$ protein functional domains. Molecular Biology and Evolution 2001, 18:917-925.

30. Porter ML, Cronin TW, McClellan DA, Crandall KA: Molecular characterization of crustacean visual pigments and the evolution of pancrustacean opsins. Molecular Biology and Evolution 2007, 24:253-268.

31. McClellan DA, Ellison DD: Assessing and improving the accuracy of detecting protein adaptation with the TreeSAAP analytical software. International J Bioinformatics Research and Application 2010, 6:120-133.
32. McClellan DA: Detecting molecular selection on single amino acid replacements. International J Bioinformatics Research and Applications 2012, 8:67-80

33. Chamala S, Beckstead WA, Rowe MJ, McClellan DA: Evolutionary selective pressure on three mitochondrial SNPs is consistent with their influence on metabolic efficiency in Pima Indians. International J Bioinformatics Research and Applications 2007, 3:504-522.

34. Beckstead WA, Ebbert MTW, Rowe MJ, McClellan DA: Evolutionary pressure on mitochondrial cytochrome $b$ is consistent with a role of cytbl7T affecting longevity during caloric restriction. PLOS ONE 2009, 4:e5836.

35. da Fonseca RR, Antunes A, Melo A, Ramos MJ: Structural divergence and adaptive evolution in mammalian cytochromes P450 2C. Gene 2007 387:58-66.

36. Osorio DS, Antunes A, Ramos MJ: Structural and functional implications of positive selection at the primate angiogenin gene. BMC Evolutionary Biology 2007, 7:167.

37. Castoe TA, Jiang ZJ, Gu W, Wang ZO, Pollock DD: Adaptive evolution and functional redesign of core metabolic proteins in snakes. PLOS ONE 2008, 3:e2201.

38. da Fonseca RR, Johnson WE, O'Brien SJ, Ramos MJ, Antunes A: The adaptive evolution of the mammalian mitochondrial genome. $B M C$ Genomics 2008, 9:119.

39. Pérez-Losada M, Viscidi RP, Demma JC, Zenilman J, Crandall KA: Population genetics of Neisseria gonorrhoeae in a highprevelence community using a hypervariable outer membrane porB and 13 slowly evolving housekeeping genes. Molecular Biology and Evolution 2005, 22:1887-1902.

40. Pérez-Losada M, Browne EB, Madsen A, Wirth T, Viscidi RP, Crandall KA: Population genetics of microbial pathogens estimated from multilocus sequence typing (MLST) data. Infection, Genetics and Evolution 2006, 6:97-112.

41. Pérez-Losada M, Crandall KA, Bash MC, Dan M, Zenilman J, Viscidi RP: Distinguishing importation from diversification of quinolone-resistant Neisseria gonorrhoeae by molecular evolutionary analysis. BMC Evolutionary Biology 2007, 7:84.

42. Taylor SD, Dittmar de la Cruz K, Porter ML, Whiting MF: Characterization of the long-wavelength opsin from Mecoptera and Siphonaptera: Does a flea see? Molecular Biology and Evolution 2005, 22:1165-1174.

43. Marques AT, Antunes A, Fernandes PA, Ramos MJ: Comparative evolutionary genomics of the $\mathrm{HADH} 2$ gene encoding $A \beta$-binding alcohol dehydrogenase/17 $\beta$-hydroxysteroid dehydrogenase type 10 (ABAD/HSD10). BMC Genomics 2006, 7:202.

44. Streisfeld MA, Rausher MD: Relaxed constraint and evolutionary rate variation between basic helix-loop-helix floral anthocyanin regulators in Ipomoea. Molecular Biology and Evolution 2007, 24:2816-2826.

45. Chapman EG, Piontkivska H, Walker JM, Stewart DT, Curole JP, Hoeh WR: Extreme primary and secondary protein structure variability in the chimeric male-transmitted cytochrome $\mathrm{c}$ oxidase subunit II protein in freshwater mussels: Evidence for an elevated amino acid substitution rate in the face of domain-specific purifying selection. BMC Evolutionary Biology 2008, 8:165.

46. Maxwell TJ, Bendall ML, Staples J, Jarvis T, Crandall KA: Phylogenetics applied to genotype/phenotype association and selection data from Angptl4 in humans. International J Molecular Sciences 2010, 11:370-385.

47. Altschul SF, Gish W, Miller W, Myers EW, Lipman DJ: Basic Local Alignment Search Tool. Journal of Molecular Biology 1990, 215:403-410.

48. Altschul SF, Boguski MS, Gish W, Wootton JC: Issues in searching molecular sequence databases. Nature Genetics 1994, 6:119-129.

49. Peetz EW, Thomson G, Hedrick PW: Charge changes in protein evolution. Molecular Biology and Evolution 1986, 3:84-94.

50. Xia X, Li W-H: What amino acid properties affect protein evolution? J Molecular Evolution 1998, 47:557-564.

51. Kawashima S, Pokarowski P, Pokarowska M, Kolinski A, Katayama T, Kanehisa M: AAindex: Amino acid database progress report 2008. Nucleic Acids Research 2008, 36:D202-D205.

52. Yang Z: PAML 4: Phylogenetic Analysis by Maximum Likelihood. Molecular Biology and Evolution 2007, 24:1586-1591.

53. Tsukihara T, Aoyama H, Yamashita E, Tomizaki T, Yamaguchi H, ShinzawaItoh K, Nakashima R, Yaono R, Yoshikawa S: The whole structure of the 13subunit oxidized cytochrome c oxidase at $2.8 \AA$ A. Science 1996 272:1136-1144

54. Kyte J, Doolittle RF: A simple method for displaying the hydropathic character of a protein. J Molecular Biology 1982, 157:105-132. 
55. Probhakaran M, Ponnuswamy PK: The spatial distribution of physical, chemical, energetic and conformational properties of amino acid residues in globular proteins. J Theoretical Biology 1979, 80:485-504.

56. Jones DD: Amino acid properties and side-chain orientation in proteins: A cross correlation approach. J Theoretical Biology 1975, 50:167-183.

57. Nozaki Y, Tanford C: The solubility of amino acids and two glycine peptides in aqueous ethanol and dioxane solutions: Establishment of a hydrophobicity scale. Journal of Biological Chemistry 1971, 246:2211-2217.

58. Zimmerman JM, Eliezer N, Simha R: The characterization of amino acid sequences in proteins by statistical methods. J Theoretical Biology 1968, 21:170-201.

59. Grantham R: Amino acid difference formula to help explain protein evolution. Science 1974, 185:862-864.

60. Fasman GD: Handbook of Biochemistry and Molecular Biology. 3 edition. CRC Press, Cleveland, Ohio; 1976, Proteins - Volume 1.

61. Gromiha MM, Ponnuswamy PK: Relationship between amino acid properties and protein compressibility. J Theoretical Biology 1993, 165:87-100.

62. Oobatake M, Ooi T: An analysis of non-bonded energy of proteins. J Theoretical Biology 1977, 67:567-584.

63. Woese CR: Evolution of the genetic code. Naturwissenschaften 1973, 60:447-459.

64. Chou PY, Fasman GD: Prediction of the secondary structure of proteins from their amino acid sequence. Advances in Enzymology and Related Areas of Molecular Biology 1978, 47:45-148.

65. Charton M, Charton B: The dependence of the Chou-Fasman parameters on amino acid side chain structure. J Theoretical Biology 1983, 102:121-134.

66. Richmond TJ, Richards FM: Packing of a-helices: Geometrical constraints and contact areas. J Molecular Biology 1978, 119:537-555.

67. Ponnuswamy PK, Prabhakaran M, Manavalan P: Hydrophobic packing and spatial arrangement of amino acid residues in globular proteins. Biochimica et Biophysica Acta 1980, 623:301-316.

68. Bhaskaran R, Ponnuswamy PK: Dynamics of amino acid residues in globular proteins. International J Peptide and Protein Research 1984, 24:180-191.

doi:10.1186/1471-2105-14-S13-S6

Cite this article as: McClellan: Directional Darwinian Selection in proteins. BMC Bioinformatics 2013 14(Suppl 13):S6.

\section{Submit your next manuscript to BioMed Central and take full advantage of:}

- Convenient online submission

- Thorough peer review

- No space constraints or color figure charges

- Immediate publication on acceptance

- Inclusion in PubMed, CAS, Scopus and Google Scholar

- Research which is freely available for redistribution

Submit your manuscript at www.biomedcentral.com/submit
Biomed Central 